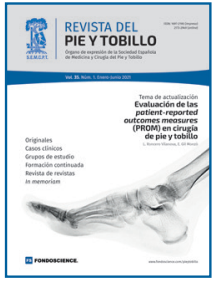

\title{
Editorial
}

\section{Cancelación temporal del formato físico de la Revista del Pie y Tobillo}

\section{Temporary cancellation of the physical format of Revista del Pie y Tobillo}

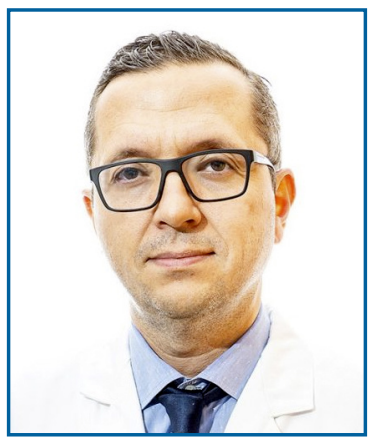

Dr. M. Herrera Pérez Director de la Revista del Pie y Tobillo

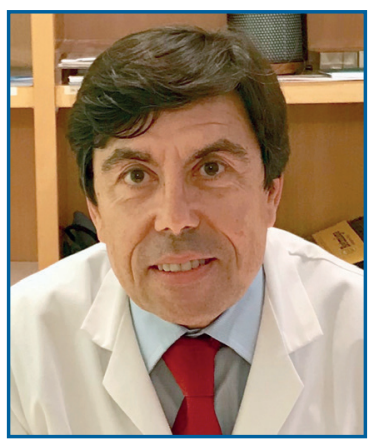

Dr. A. Dalmau Coll Presidente de la SEMCPT
Estimados compañeros:

Para ninguno de nosotros es novedad que corren tiempos muy complejos para la ciencia, la salud y también la actividad económica de nuestro país, con el enorme impacto de la pandemia por COVID-19. El año 2020 y lo que llevamos de este 2021 han supuesto un decremento histórico en los ingresos para las arcas de la sociedad, pues recordemos que la principal fuente de financiación, que era el congreso nacional, tuvo que ser suspendido en su forma presencial, al igual que ha ocurrido con el presente congreso de 2021.

A esta situación, hay que añadir la importante repercusión que el cese de la actividad quirúrgica nacional ha tenido en las principales empresas de material quirúrgico que colaboraban económica y científicamente con nuestra sociedad.

Pues bien, ante esta situación única y especialmente delicada, la Junta Directiva de la SEMCPT, en representación de los socios y con el principal y único objetivo de la salvaguarda de la viabilidad económica de la misma, ha decidido llevar a cabo una serie de medidas de ahorro económico, con la eliminación de algunas actividades e inversiones que hemos considerado prescindibles. Dentro de estas medidas, se ha decidido la suspensión temporal de la publicación en forma impresa o física de la Revista de Pie y Tobillo, lo que supone un ahorro económico relevante, teniendo en cuenta que se realizaba la impresión de 100 ejemplares y su correspondiente distribución postal (siendo 6 ejemplares enviados a ultramar).

Somos conscientes de la relevancia de esta medida y del desacuerdo que muchos socios mostrarán, pero hemos valorado a conciencia las consecuencias 
y creemos que en este momento debemos actuar de esta manera, dejando la puerta abierta a retomar esta publicación impresa cuando las condiciones económicas así lo permitan.

Sin otro particular y agradeciendo tu comprensión en estos tiempos muy convulsos, esperamos que esta situación se solvente lo antes posible.

Atentamente,

Mario Herrera Pérez

Director de la Revista del Pie y Tobillo

\author{
Antonio Dalmau Coll \\ Presidente de la \\ SEMCPT
}

